\title{
First two decades of British rheumatology: a personal perspective
}

\author{
George D Kersley
}

Although it was not until 1932 that the Royal College of Physicians set up its Committee for the Study of Classification and Nomenclature of the Rheumatic Diseases, it was the figures published by Alison Glover of the Ministry of Health from 1924 to 1928 on its incidence that promoted the first interest. The chairman of the committee was Sir Humphrey Rolliston with Sir Robert Hutchinson as president, but it was Lord Horder's interest and energy that established the Empire Rheumatism Council (ERC) in 1936 when the committee had completed its task. Charles Buckley continued the College Reports as the Annals of the Rheumatic Diseases and Horder became chairman with W S Copeman as medical secretary of the ERC.

Will Copeman was the first medical consultant to pin his career to the mast of rheumatology and I tried, though much his junior, to follow in his footsteps. Perhaps by coincidence we both were first interested in paediatrics, but were told that the study of sick children was essentially general medicine and not a specialty for ordinary men, with only a place for a couple of academics at its head.

It was Copeman and Horder who were mainly responsible for establishing the ERC, which after budding off the Canadian, Australian, and New Zealand Councils became the ARC in 1964 and has been responsible for most of our advances in research and teaching.

On the more clinical side the Heberden Society was developed from the staff of the Peto Place BRCS Rheumatology Clinic in 1937 with Frank Howitt and then Mathew Ray as chairman. Copeman again played a large part, fighting for rheumatology to become and remain a respectable specialty of general medicine, thus later bringing him into conflict with physical medicine, in case the latter should reverse rheumatology's trend to be accepted by the academics.

It was in 1932, after taking the Membership, that I realised that I would have been happier with a question on a rare brain tumour than on arthritis! I told Francis Fraser, then professor of medicine at Barts, later moving to Hammersmith, that I wanted to make a study of the rheumatic diseases. He was horrified that I should be associating myself with the 'quacks', till I pointed out that this was essential if we were to make progress on this widespread group of diseases. Horder, however, gave me great encouragement.

With little hope of progress at Barts, Bath seemed the obvious place with the Royal Mineral Water Hospital and also the Royal United, then the best non-teaching voluntary hospital in the country, so that I could also keep my contact with general medicine. In those days, before the National Health Service, if appointed as consultant, one received no pay, but became also a general practitioner, or in rheumatology perhaps did some Spa work, to earn one's living until gradually one built up a consultant practice.

The Spa hospitals were the centres for treatment of arthritis with Buckley and Hill at Buxton, Edgecombe and Yeomans at Harrogate, and Vincent Coates, who was disastrously killed in a rail accident, and whom I joined at Bath. At that time any patients who might get benefit from the 'waters' were admitted, even for gall stones, which the waters might wash away! In 1936 however the Royal Mineral Water Hospital changed its name to the Royal National Hospital for Rheumatic Diseases, signifying the intention to treat arthritis with all methods that might be helpful to the condition.

Neglect of treatment for arthritis had led to horrendous results - old women with rheumatoid arthritis crippled with their knees under their chins and nails grown through to the back of their clenched hands and spondylitics so bent that they could see better backwards through their legs than in front of them when standing.

With developments at the Spa hospitals and in London with Eric Bywaters and Kellgren in the academic and research sphere and those like Frank Dudley Hart doing rheumatology, with one foot firmly in general medicine, the subject was becoming more respectable. Then came the second world war and rehabilitation became the need. Frank Howitt was in 1941 appointed brigadier to collect a team to do physical medicine and he selected from the available rheumatologists in civilian work, except for myself who had been in the North Somerset Yeomanry and had already become a medical specialist-TA. The team consisted of Drs Davies, Duthie, Patterson, Tegner, Tierney, Wilson and me. Frank Cooksey took over the role in the EMS.

After the war the conflict arose between rheumatology and rehabilitation as to whether to separate or fuse. Protagonists of the former, such as Copeman and Bywaters, wanted to protect the reputation of rheumatology while the latter, like Howitt and Cooksey, wished for fusion and were interested in acquiring hospital beds and private practice.

This situation was further confused by the Ministry of Health, as when Horder, Copeman, Bywaters, and I went to see Ian Macleod to ask for registrars in rheumatology, we were told we had them, but that they were called registrars in physical medicine!

Finally, in the late ' 40 s came the discovery of cortisone by the rheumatologist, Phil Hench and stress syndromes by Hans Selye, and this did much to convince the academics that rheumatology was at last an undisputed respectable specialty of general medicine. 